\title{
Role of Oral Misoprostol in First Trimester Abortion: A Prospective Study at CMH, Dhaka, Bangladesh
}

\author{
S. K. Chowdhury ${ }^{1}$, M. Z. Hussain ${ }^{2}$ \\ ${ }^{1}$ Combined Military Hospital, Dhaka, Bangladesh \\ ${ }^{2}$ Border Guard Hospital, Peelkhana, Dhaka, Bangladesh \\ Email: skcshahanaz@gmail.com,mzhzakir@gmail.com
}

How to cite this paper: Chowdhury, S.K. and Hussain, M.Z. (2020) Role of Oral Misoprostol in First Trimester Abortion: A Prospective Study at $\mathrm{CMH}$, Dhaka, Bangladesh. Open Journal of Obstetrics and Gynecology, 10, 179-186.

https://doi.org/10.4236/ojog.2020.1010015

Received: December 9, 2019

Accepted: January 10, 2020

Published: January 13, 2020

Copyright ( 2020 by author(s) and Scientific Research Publishing Inc. This work is licensed under the Creative Commons Attribution International License (CC BY 4.0).

http://creativecommons.org/licenses/by/4.0/

\begin{abstract}
Background: Misoprostol has been used for medical abortion. We conducted this prospective study to see the efficacy of oral misoprostol in our tertiary Hospital. Objective: Objective of this study was to assess the efficiency, safety and compliance of misoprostol in first trimester abortion. Materials and $\mathbf{M e}$ thods. This prospective study was undertaken in obstetrics and gynecology dept of CMH Dhaka, Bangladesh from July 2014 up to Dec 2014. A total 50 patients of incomplete abortion (54\%), missed abortion (30\%), anembryonic pregnancy (14\%) and inevitable abortion $(2 \%)$ of $<13$ weeks of gestation were the targeted population. Study population was diagnosed from history, physical examination and ultrasonogram had received 600 microgram misoprostol orally. If the pregnancy was not completely evacuated at this time another dose of misoprostol was given. All women returned for follow-up care 7 days later. If the pregnancy was not completely evacuated at this time, women underwent immediate surgical evacuation. Efficacy was defined as the percent of women discharged from the study without need for surgical intervention. Results: 30 patients had complete evacuation after $1^{\text {st }}$ dose, 12 cases needed $2^{\text {nd }}$ dose and only 2 cases needed $3^{\text {rd }}$ dose. Remaining 6 cases needed surgical evacuation. Efficacy was satisfactory (85\%) and analysis revealed statistically significant $(\mathrm{p}<0.05)$. Conclusion: Management of first trimester abortion with oral misoprostol is highly effective and highly acceptable.
\end{abstract}

\section{Keywords}

Role of Oral Misoprostol, First Trimester Abortion

\section{Introduction}

Misoprostol, a prostaglandin analogue, increases the frequency of uterine con- 
tractions, which is responsible for its abortifacient capability and ability to promote labor and cervical ripening. First trimester abortion is one of the most common clinical problems in our daily gynecological practice. The definition of abortion is the termination of pregnancy by any means before the fetus is sufficiently developed to survive [1]. According to surveillance data from the Centers for Disease Control and Prevention (CDC), 12\% of abortions occur within 13 weeks' gestation, which is known as first trimester abortion [2]. Since 1930 abortion has traditionally been managed with surgical evacuation [3]. These surgical procedures have some inadvertent complications [4]. Approximately 28,000 women in Bangladesh die each year due to abortion-related complications which are about one-fourth of total maternal mortality (1.67/1000 live birth) [5] [6]. In our country the abortion related death was found to be $5 \%$ of maternal death [6]. In years 2004 Abortion complications are responsible for the death of nearly $25 \%$ of the mothers (MOHFW 2004) [7]. The WHO estimates that about $20 \%$ $30 \%$ of unsafe abortions result in reproductive tract infections and that about $20 \%-40 \%$ of these result in upper-genital-tract infection and infertility. An estimated $2 \%$ of women are infertile as a reproductive age result of unsafe abortion, and 5\% have chronic infections. Unsafe abortion could also increase the long-term risk of ectopic pregnancy, premature delivery, and spontaneous abortion in subsequent pregnancies [8]. It has been estimated that $13 \%$ of all maternal death worldwide are due to unsafe abortion. In recent times medical evacuation of the uterus with misoprostol is being used increasingly and rapidly replacing the surgical approach [9]. It is simple, non-invasive, less complicated, reducing the cost of service, well tolerated and acceptable for the patient [10]. Some studies showed that vaginal application of misoprostol increases the success rate and reduces the side effects [11]. A large number of studies have shown that misoprostol is highly effective in first trimester abortion [12]. In this study misoprostol has been selected as a large number of patients can be benefited and escape from surgical intervention and complications. Misoprostol interacting with prostaglandin receptors causes the cervix to soften by collagenolytic activity and uterus to contract, resulting in the expulsion of the uterine content [13]. There are some side effects of misoprostol such as nausea, vomiting, abdominal cramps, diarrhoea, vaginal bleeding, dizziness, headache, low grade fever, rashes and dose depended uterine hyperstimulation. In most cases, side effects and pelvic pain can be managed with oral analgesics [14]. "No health without reproductive health", to emphasis this motto we select and work on this topic.

\section{Methodology}

This study involved data collection by a standard data collection form, in all women admitted to CMH Dhaka, Bangladesh between July 2014 up to Dec 2014 with first trimester abortion during study period. Total 50 patients of incomplete abortion (54\%), missed abortion (30\%), anembryonic pregnancy (14\%) and inevitable abortion $(2 \%)$ of $<13$ weeks of gestation were the targeted population. 
After getting ethical clearance from proper authotity (CMH, Dhaka, Bangladesh) the following steps was taken during data collection (keeping in the mind that variables are age and parity), after admission informed verbal consent was taken from the patient and selected by standard data collection form, condition of the patient was diagnosed by history, physical examination and by the help of base line investigations including USG of uterus to confirm the diagnosis of incomplete, missed, anembryonic abortion. All women who fulfill the inclusion criteria was received 600 microgram misoprostol orally, the dose was repeated every 4 hours if needed. Follow up was done after 4 hours interval or whenever the patient complains of any problem. Interval between administration of misoprostol and expulsion of product of conception was recorded. If expulsion does not occur within 24 hours, oxytocin infusion was started $4-6$ hours after the last dose of misoprostol. In spite of misoprostol and oxytocin if the patient fails to respond surgical evacuation was attempted. Ultrasonography was done after 12 24 hours to confirm complete expulsion. If complete expulsion occurs patient was discharged from the hospital and instructed to come to hospital on day $8^{\text {th }}$ to see the completeness of expulsion of product by USG. If USG shows incomplete expulsion than surgical evacuation was done. Every woman was advised to come for follow up on $15^{\text {th }}$ day. Descriptive statistics for prevalence was done. Chi-square test to find an association between the age and parity was performed. In this study we assess the efficacy and effectiveness of misoprostol in our institute and we satisfied with result.

\section{Results}

In this study most of the women belonged to age group 20 - 24 years (38\%) and $26(52 \%)$ were nulliparous. A total $28(56 \%)$ cases were between $9-13$ wks of gestation (Table 1). Clinical types of pregnancy loss were mostly incomplete abortion 27 (54\%), only inevitable abortion 1 (2\%) (Table 2). In most cases expulsion occurred within 24 hours of application of misoprostol. Among them maximum 26 (52\%) were 12 - 24 hours group (Table 3). Out of 50 cases maximum $30(60 \%)$ patient had complete evacuation after first dose and $2(4 \%)$ remain incomplete which needed surgical evacuation (Table 4). Only few percent shows mild side effects. Among them 13 (26\%) was mild to moderate abdominal cramp (Table 5). Only 2 (4\%) patient needed blood transfusion (Table 6). This modality of treatment was well accepted $41(82 \%)$ and rest of the case were not satisfied with this treatment (Table 7).

\section{Discussion}

Our study indicates that treatment of early pregnancy loss with 600 microgram misoprostol orally the dose repeated after 24 hours when necessary is efficacious, a safe and effective nonsurgical option for the treatment of first trimester abortion. The success rate by 48 hours was $88 \%$. The risk of diarrhoea and abdominal cramps were minimum and the side effects were tolerable. Misoprostol used in 
Table 1. Demography of the women values are given in number and percentage.

\begin{tabular}{cccccc}
\hline & $\begin{array}{c}\text { No of Cases } \\
(\mathrm{n}=50)\end{array}$ & $\%$ & Mean $+\mathrm{SD}$ & $\mathrm{X}^{2}$ & P value \\
\hline 15y - 19y & 5 & 10 & & \\
$20 \mathrm{y}-24 \mathrm{y}$ & 19 & 38 & $25.96+5.83$ & & \\
$25 \mathrm{y}-29 \mathrm{y}$ & 12 & 24 & & \\
$>30 \mathrm{y}$ & 14 & 28 & & \\
& & & & \\
Nullipara & 26 & 52 & & \\
Primipara & 11 & 22 & & \\
Multipara & 13 & 26 & & \\
& & & & \\
$<6$ weeks & 8 & 16 & & \\
7 - 8 weeks & 14 & 28 & & \\
9 - 13 weeks & 28 & 56 & & \\
\hline
\end{tabular}

Table 2. Clinical types of pregnancy loss.

\begin{tabular}{ccc}
\hline Clinical types & Number of cases $(\mathrm{n}=50)$ & $\%$ \\
\hline Missed abortion & 15 & 30 \\
Incomplete abortion & 27 & 54 \\
Inevitable abortion & 1 & 14 \\
Anembryonic pregnancy & 7 & 2 \\
\hline
\end{tabular}

Table 3. Length of time between ingestion of misoprostol and expulsion of product of conception.

\begin{tabular}{ccc}
\hline Time & Number of case $(\mathrm{n}=50)$ & $(\%)$ \\
\hline$<6$ hours & 7 & 14 \\
$6-12$ hours & 11 & 22 \\
$12-24$ hours & 26 & 52 \\
$24-48$ hours & 6 & 12 \\
\hline
\end{tabular}

Table 4. Percentage of complete/incomplete expulsion following ingestion of misoprostol.

\begin{tabular}{ccccccc}
\hline \multirow{2}{*}{$\begin{array}{c}\text { Management protocol } \\
\text { with dose }\end{array}$} & Complete & Incomplete & $\begin{array}{c}\text { Total } \\
(\mathrm{n}=50)\end{array}$ & Percentage & $\mathrm{X}^{2}$ & P value \\
\cline { 2 - 5 } evacuation & evacuation & 30 & 33 & 66 & & \\
\hline 1st dose & 30 & 3 & 13 & 26 & 26.44 & 0.001 \\
2nd dose & 12 & 1 & 4 & 8 & & \\
\hline
\end{tabular}


Table 5. Side effects reported by the patient.

\begin{tabular}{ccc}
\hline Side effect & Number of case & Percentage (\%) \\
\hline Abdominal cramp & 13 & 26 \\
Nausea & 11 & 22 \\
Vomiting & 1 & 2 \\
Diarrhoea & 6 & 12 \\
Fever & 4 & 8 \\
Headache & 2 & 4 \\
Hot flash & 1 & 2 \\
Dizziness & 1 & 2 \\
\hline
\end{tabular}

Table 6. Status of blood transfusion.

\begin{tabular}{ccccc}
\hline Blood transfusion & No of cases $(\mathrm{n}=50)$ & $\%$ & $\mathrm{X}^{2}$ & P value \\
\hline Required & 2 & 4 & 42.32 & 0.001 \\
Not required & 48 & 96 & & \\
\hline
\end{tabular}

Table 7. Compliance.

\begin{tabular}{ccccc}
\hline Compliance & No of case $(\mathrm{n}=50)$ & $\%$ & $\mathrm{X}^{2}$ & P value \\
\hline Accepted by the responder & 41 & 82 & & 0.001 \\
Not accepted by the responder & 9 & 18 & & 20.48 \\
\hline
\end{tabular}

this study was found to be efficacious. Moreover it is stable at room temperature and cheaper than other expensive conventional prostaglandins. Only few side effects of misoprostol were observed in our cases. In study of NTN Ngoc et al. showed treatment of missed abortion by 800 microgram of misoprostop orally efficacy $89 \%$ and the mean time of expulsion were 21 hours [11]. Haberal A et al. showed treatment with oral misoprostol 200 microgram given once an hour (minimum 200 microgram-max 1200 microgram) in early complicated missed abortion and anembryonic pregnancy complete abortion $92.5 \%$ within 12 hours [15]. Blanchard K et al. showed that, Women received either single or repeated dose of $600 \mathrm{mcg}$ of misoprostol taken orally. Follow-up was conducted two weeks following misoprostol administration. $66 \%$ of women in the single dose arm and $70 \%$ of women in the repeated dose are experienced complete expulsion without the need for surgical intervention [16]. Zabeena Pandian et al. treated 112 women with incomplete miscarriage at less than 13 weeks gestation using 600 microgram oral misoprostol followed by two further oral dose of $400 \mathrm{mi}$ crogram misoprostol 2 hours interval. They reported $85 \%$ had complete uterine evacuation without the need for surgical evacuation [17]. Vorapong Phuponga et al. showed that 100 women treated with oral misoprostol single 600 microgram versus repeated oral dose 600 microgram 4 hourly up to 1200 microgram in incomplete abortion. Complete expulsion occurred in $86.9 \%$ cases [18]. The 
present study using the 600 microgram of misoprostol orally 24 hours apart $85 \%$ success rate by 48 hours the criterion for complete expulsion was same. Ultrasound was done transabdominally instead of transvaginally. The advantage of the regime of the present study and the Vorapang et al., it avoids considerable number of operation and when complete expulsion does not occur it usually provides adequate cervical dilation making surgical evacuation easy and complicated, duration of hospital stay is less. No significant side effects were observed in the various studies describer above $1 \%-2 \%$ of women developed intense bleeding and only $4 \%$ required blood transfusion. Misoprostol treatment was acceptable to most women. We found that women with incomplete or inevitable spontaneous abortion were more likely to have complete expulsion after one dose of misoprostol than were women with embryonic or fetal death or women with an anembryinic gestation. However by using a second dose, if expulsion is incomplete, a similarly high success rate. We waited 24 hours between doses in an attempt to allow sufficient time for the initial dose to be effective. The majority of the women in our study reported satisfaction with this approach. In our study almost all women with an endometrial thickness of $<20$ mm by ultrasonography after misoprostol treatment complete expulsion uneventfully. It is not known whether 600 microgram of misoprostol represent the lowest effective dose for all subtypes of early pregnancy loss. Another observation in our study was that there were additional benefits of using misoprostol treatment which were not completely successful. All the patients who needed surgical evacuation had soft and dilated cervix at the time of surgical evacuation, which reduced the risk of perforation and cervical injury. From this study it is anticipated that medical management of early pregnancy loss with oral misoprostol will prove to be a good.

Our trial involved a 15 days follow up period. The vast majority of patients recovered satisfactorily within this period (88\%). In some patients tissue was often seen in internal os. Who come for follow up visit, it was removed in many cases with sponge holding forceps without further treatment. Only 6 women required surgical intervention. In follow up period only few patient complaints per vaginal bleeding and USG finding showed complete evacuation of uterus. Our study included an incomplete abortion, inevitable abortion, missed abortion, anembrionic gestation less than 13 weeks size. In addition women who were having slight per vaginal bleeding, when they present to the hospital were included in our study.

Limitation of the study: we didn't face any difficulty during study. Study population may be increased in this study. Number of variables may increase.

\section{Conclusion}

We study only oral administration of misoprostol. Previous randomized trials have indicated that the effect of misoprostol is similar whether it is administered vaginally or orally, whereas the incidence of diarrhea occurred less frequently in 
the single dose group. Despite many side effects, management of first trimester abortion with oral misoprostol is highly effective and highly acceptable.

\section{Conflicts of Interest}

The authors declare no conflicts of interest regarding the publication of this paper.

\section{References}

[1] Malhotra, N., Kumar, P., Malhotra, J., Bora, N.M. and Mittal, P. (2008) Jeffcoate's Principles of Gynaecology. 7th Edition, Arnold, London.

[2] Strauss, L., Gamble, S., Parker, W., et al. (2007) Abortion Surveillance-United States. MMWR Morbidity and Mortality Weekly Report, 56, 1-33.

[3] Pang, M.W., Lee, T.S. and Chung, T.K.H. (2001) Incomplete Miscarriage: Randomized Controlled Trial Comparing Oral with Vaginal Misoprostol for Medical Evacuation. Human Reproduction, 16, 2283-2287.

https://doi.org/10.1093/humrep/16.11.2283

[4] Demetroulis, C., Saridogan, E., Kunde, D. and Naftatin, A.A. (2001) A Prospective Randomized Trial Comparing Medical \& Surgical Treatment for Early Pregnancy Failure. Human Reproduction, 16, 365-369. https://doi.org/10.1093/humrep/16.2.365

[5] Khan, M.E. and Ismail Hossain, S.M. (2001) Introducing Emergency Contraception in Bangladesh: A Feasibility Study. Research Update 1. Population Council/FRONTERS, Dhaka, Bangladesh.

[6] Obstetrical and Gynaecological Society of Bangladesh (1993) In Emergency Obstetric Care: Intervention for the Reduction of Maternal Mortality, 1-2.

[7] Bangladesh, Ministry of Health and Family Welfare (2004) Bangladesh National Strategy for Maternal Health. MOH \& FW, Dhaka.

[8] World Health Organization (2004) Unsafe Abortion: Global and Regional Estimates of the Incidence of Unsafe Abortion and Associated Mortality. 4th Edition, World Health Organization, Geneva, Switzerland.

[9] Granziosi, G.C.M., Vander Steeg, T.W., et al. (2005) Economic Evaluation of Misoprostol in the Treatment of Early Pregnancy Failure Compared to Curettage after an Expectant Management. Human Reproduction, 20, 1067-1071.

https://doi.org/10.1093/humrep/deh709

[10] Bagratee, J.S., Khullar, V., Regan, L., Moodley, J. and Kagoro, H. (2004) Arandomized Controlled Trial Compairing Medical and Expected Management of First Trimester Miscarriage. Human Reproduction, 19, 266-271. https://doi.org/10.1093/humrep/deh049

[11] Ngoe, N.T.N. and Blum, J. (2004) Medical Treatment of Missed Abortion Using Misoprostol. International Journal of Gynaecology \& Obstetrics, 87, 138-142. https://doi.org/10.1016/j.ijgo.2004.07.015

[12] Baird, D. (2000) Mode of Action of Medical Method of Abortion. Journal of the American Medical Women's Association, 35, 121-126.

[13] Tang, O.S., Mock, K.H. and Ho, P.C. (2004) A Randomized Study Comparing the Use of Sublingual to Vaginal Misoprostol for Pre Operative Cervical Priming Prior to Surgical Termination of Pregnancy in the First Trimester. Human Reproduction, 19, 1101-1104. https://doi.org/10.1093/humrep/deh143 
[14] Lanza, F.L., Chan, F. and Quigley, E. (2009) Guidelines for Prevention of NSAID-Related Ulcer Complications. American Journal of Gastroenterology, 104, 728-738. https://doi.org/10.14309/00000434-200903000-00035

[15] Haberal, A., Celikkanat, H. and Batioglu, S. (1996) Oral Misoprostol Use in Early Complicated Pregnancy. Advances in Contraception, 12, 139-143. https://doi.org/10.1007/BF01849635

[16] Blanchard, K., Taneepanichskul, S., Kiriwat, O., Sirimai, K., Svirirojana, N., Mavimbela, N. and Winikoff, B. (2004) Two Regimens of Misoprostol for Treatment of Incomplete Abortion. Obstetrics and Gynecology, 103, 860-865. https://doi.org/10.1097/01.AOG.0000124274.47717.a7

[17] Pandian, Z., Ashok, P. and Templeton, A. (2001) The Treatment of Incomplete Miscarriage with Oral Misoprostol. British Journal of Obstetrics and Gynaecology, 108, 213-214. https://doi.org/10.1016/S0306-5456(00)00024-3

[18] Phuponga, V., Taneepanichskula, S. and Kriengsinyota, R. (2004) Comparative Study between Single Dose 600 Microgram and Repeated Dose of Oral Misoprostol for Treatment of Incomplete Abortion. Contraception, 70, 307-311. https://doi.org/10.1016/j.contraception.2004.04.002 